\title{
Can an Emoji Be Considered as Defamation? \\ A Legal Analysis of Burrows v Houda [2020] \\ NSWDC 485
}

P Singh*

\section{P.E.R}

Pioneer in peer-reviewed,

open access online law publications

Author

Priya Singh

Affiliation

University of KwaZulu-Natal

South Africa

Email

singhpp@ukzn.ac.za

Date Submission

21 September 2020

Date Revised

15 March 2021

Date Accepted

15 March 2021

Date published

14 April 2021

Editor Dr N Kilian

How to cite this article

Singh P "Can an Emoji Be

Considered as Defamation? A

Legal Analysis of Burrows $v$ Houda

[2020] NSWDC 485" PER / PELJ

2021(24) - DOI

http://dx.doi.org/10.17159/1727

$3781 / 2021 / v 24 i 0 a 8918$

\section{Copyright}

DOI

http://dx.doi.org/10.17159/1727-

$3781 / 2021 / v 24 i 0 a 8918$

\begin{abstract}
This article considers the Australian case of Burrows $v$ Houda 2020 NSWDC 485 and the English case of Lord McAlpine $v$ Bercow 2013 EWHC 1342 (QB). Both cases considered the question of whether emojis could be considered to be defamatory and answered the question in the affirmative. This article also explores whether the South African courts will follow the lead of the Australian and English courts and concludes that emojis also have the potential to be considered defamatory in our law.
\end{abstract}

\section{Keywords}

Defamation; emoji; emoticon; tort; delict; Burrows v Houda; Lord McAlpine $v$ Bercow. 


\section{Introduction}

In August 2020 an Australian court heard the novel matter of Burrows $v$ Houda (hereafter the Burrows case) and was called upon to decide whether the use of the "zipper-mouth emoji" could be considered as defamatory. ${ }^{1}$ The court ruled on $27^{\text {th }}$ August 2020 that the use of this emoji was capable of giving rise to a defamatory meaning. This is merely a preliminary ruling in the matter and the matter is currently ongoing.

An emoji is "a small digital image or icon used to express an idea, emotion, etc., in electronic communications". ${ }^{2}$ Pelletier states that:

[e]mojis are often included alongside text to portray an emotion or otherwise add to readers' understanding of the text. The most basic emoji is a yellow smiley face, but emojis span from face emotions, like happy, sad, and angry, to animals and ordinary objects, like a cat or a briefcase. With such options, tweets are largely only limited by individual users' creativity. ${ }^{3}$

Emojis can be included in text messages, emails and messages, and posts on social media sites, and blogging or other sites. Emojis can also be thought of as playing "a role in social media analogous to non-verbal behaviour in offline speech"4 and they attempt to "smooth out the rough edges of digital life." Some writers have even gone so far as to state that "[o]ver time, it will feel increasingly 'weird' and 'creepy' to write online messages without emojis." 6

McMahon and Kirley postulate that while emojis are widely perceived as "cute or benign adjuncts to online communications" and are used to "humanize truncated digital messages by conveying humor (sic) emotion, and sociability, emoji (can) perform a far more sinister role." ${ }^{77}$ This sinister role includes its use in hate speech, cyber-bullying, witness intimidation, online grooming of children for sexual abuse, and other crimes. ${ }^{8}$

There are currently almost 3300 different emojis in existence ${ }^{9}$ and July 17 has been designated World Emoji Day. It is estimated that approximately

\footnotetext{
* Priya Singh. BCom LLB(UN) LLM (UKZN). Lecturer, University of KwaZulu-Natal, School of Law, South Africa. Email: singhpp@ukzn.ac.za. ORCiD: https://orcid.org/0000-0003-1554-3414.

Burrows v Houda 2020 NSWDC 485.

Burrows v Houda 2020 NSWDC 485 paras 20-21.

Pelletier 2016 Wash U J L \& Pol'y 229.

Kirley and McMahon 2018 Tenn L Rev 517.

Stark and Crawford $2015 S M+S$.

Goldman 2018 Wash L Rev 1229.

McMahon and Kirley 2019-2020 MJLST 37.

McMahon and Kirley 2019-2020 MJLST 42-43.

Unicode 2020 https://unicode.org/emoji/charts/emoji-counts.html.
} 
700 million emojis are used daily in Facebook posts and that over 900 million emojis are sent as standalone messages (i.e. without any accompanying text) on Facebook Messenger. ${ }^{10}$ Over 10 billion emojis are used daily and $95 \%$ of internet users have used an emoji, with studies showing that the use of emojis in a social media post can increase engagement with that post: ranging from an increase on Twitter of $25.4 \%$ and increasing the amount of likes on Facebook by $57 \%$ and the number of comments on posts by $33 \% .{ }^{11}$ Additionally, emojis are also effective in digital marketing, as commercial emails which include an emoji in their email subject lines, have a higher unique open rate than emails that did not contain emojis in their subject lines.

With these figures, it is safe to state that the use of emojis is here to stay. As such, our courts will have to increasingly engage with the impact of these emojis in different areas of the law. Courts in the USA have had to decide whether the use of emojis can be considered as criminal intimidation, ${ }^{12}$ and online sexual grooming of children by paedophiles. ${ }^{13}$ In this article we explore whether emojis can be considered as defamatory.

This note will first discuss the general law relating to defamation in Australia, as a backdrop to an exploration of the Burrows case. Next, it will briefly discuss the English case of Lord McAlpine of West Green $v$ Bercow (hereafter referred to as the Bercow case), before hypothetically discussing whether an emoji could be held to be defamatory in the context of South African law.

\section{General background to Australian defamation law}

The law of defamation in Australia is governed largely by a combination of common law and the Defamation Act. ${ }^{14}$ The common law is inherited mainly from the English law of defamation, and it has been developed by the Australian courts over many decades. Each of the states and territories of Australia has also modified the common law by introducing statutes which apply to that state or territory. However, each of these individual statutes is

\footnotetext{
10 SouthFloridaReporter.com 2020 https://southfloridareporter.com/\%F0\%9F\%98\% 84-95-of-internet-users-have-used-an-emoji-over-10-billion-emojis-are-sent-daily/. SouthFloridaReporter.com 2020 https://southfloridareporter.com/\%F0\%9F\%98\% 84-95-of-internet-users-have-used-an-emoji-over-10-billion-emojis-are-sent-daily/. People v Smith No B284766, 2019 Cal App Unpub LEXIS 1691, at *2 (Cal Ct App Mar 12, 2019); United States v Elonis 730 F 3d 321, 323 (3d Cir 2013).

13 State $v$ Atchison 15 Neb App 422, 424-25 (2007).

14 Defamation Act of 2005.
} 
underpinned by the universally applicable Model Defamation Provisions introduced in 2005. ${ }^{15}$

In order for a defamation action to be founded in Australia, the material must be published to a person who is capable of understanding it to be defamatory. This person must be an individual other than the plaintiff and the publication must be intentional or a probable result arising from the defendant's conduct. As in South Africa, a person who republishes a defamatory statement can also be held liable for it. ${ }^{16}$ There may also be instances of multiple publishers, in that the author, the printer, the publisher and the distributor may all be held liable for defamatory material published by them.

The publisher of the defamatory material will be held liable even if he acted with reasonable care or there was no intention on his part to cause the plaintiff any damages. ${ }^{17}$

Australian law has deemed the owner of a website that publishes defamatory material to be the publisher of that material. ${ }^{18}$

The Australian courts have recently decided on many matters which are relevant to internet and social media usage. In Trkulja $v$ Yahoo! Inc. LLC the court ruled that search engines (such as Google) could be deemed to be publishers and can be sued for defamation for defamatory material appearing on their search engines. ${ }^{19}$ They would, however, be able to use a defence of innocent dissemination to escape liability in appropriate cases.

The defence of innocent dissemination was further considered by the Australian courts in Duffy $v$ Google $I n c^{20}$ and the subsequent appeal in Google Inc $v$ Duffy. ${ }^{21}$ In the appeal case the South Australian Supreme Court held that an internet publisher could be held liable as a secondary publisher of defamatory material posted on its site if it failed to block the defamatory material after it became aware of the defamatory nature of the material. The court further held that Google could be held liable, even

Original Model Defamation Provisions of 2005.

For Australian law see Lewis v Daily Telegraph Ltd 1964 AC 234 283-284; Speight $v$ Gosnay 189160 LJQB 231; Sims v Wran 19841 NSWLR 317 320. For South African law see Mograbi v Miller 19564 SA 239 (T); Hassen v Post Newspapers (Pty) Ltd 19653 SA 562 (W) 564-565.

Lee v Wilson 193451 CLR 276; 1934 HCA 6.

Al Muderis v Duncan (No 3) 2017 NSWSC 726.

Trkulja v Yahoo! Inc LLC 2012 VSC 88.

Duffy v Google Inc 2015125 SASR 437.

Google Inc v Duffy 2017129 SASR 304. 
though the defamatory material was available elsewhere on the internet and appeared on the results of the Google search engine only.

Search engines such as Google can also be held liable for defamation for the results of auto-predicted searches. This was established in Trkulja $v$ Google, in which Trkulja sued Google for defamation as an auto-predicated search result linked him to organised crime. ${ }^{22}$

The very recent case of Voller v Nationwide News Pty Ltd; Voller v Fairfax Media Publications Pty Ltd; Voller v Australian News Channel Pty Ltd, dealt with the issue of the liability of social media platforms for defamation. ${ }^{23}$ The plaintiffs alleged that third parties had made defamatory posts regarding them on the defendants' Facebook page. They alleged that the defendants should be held liable for these defamatory posts. The court agreed with the plaintiff's submissions and held that the social media platforms and media companies could be considered to be publishers of defamatory posts made on their public Facebook pages. ${ }^{24}$ This decision is currently being appealed.

It is interesting to note that while a South African court may order an apology in defamation matters, an Australian court may not make this order, and the usual Australian remedy is a damages award. ${ }^{25}$

The Australian courts have dealt with many more facets of internet and social media defamation than the South African courts. One should, however, bear in mind the warning of legal experts in Australia that:

Australia has become the defamation capital of the world, with twice as many libel claims as the United Kingdom despite having well under half its population ... 'we inherited the English common law and then made it worse. ${ }^{26}$

All Australian jurisdictions approved amendments to the Australian Model Defamation Provisions in July 2020, at a meeting of the Council of AttorneyGenerals. ${ }^{27}$

Current proposed amendments include the provision of a new "serious harm" requirement, the introduction of new defences, including a "public

Trkulja v Google LLC 2018 HCA 25.

Voller v Nationwide News Pty Ltd; Voller v Fairfax Media Publications Pty Ltd; Voller $\checkmark$ Australian News Channel Pty Ltd 2019 NSWSC 766.

This is also the position in South African law. See Dutch Reformed Church Vergesig $v$ Sooknunan 20126 SA 201 (GSJ) discussed below. Le Roux v Dey 20113 SA 274 (CC).

Pelley 2019 https://www.afr.com/companies/media-and-marketing/australia-thedefamation-capital-of-the-world-20190904-p52nuh.

Douglas $2020 \mathrm{https}$ ://theconversation.com/australias-outdated-defamation-lawsare-changing-but-theres-no-revolution-yet-143532. 
interest" defence based on the English law, and amendments to the capping of damages.

Australia is also investigating legislative changes to allow social media companies to be held liable for defamatory comments made by third parties on their platforms. While the common law already allows for this, as established in the Voller case above, that judgment is currently being appealed.

The cross-border global nature of social media networking sites raises interesting Public Interest litigation issues especially around the issues of holding social media companies liable in situations where the social media company is not based in the country of origin of the litigation. Most social media companies are based in the United States of America, whose laws provide that "no provider or user of an interactive computer service shall be treated as the publisher or speaker of any information provided by another information content provider."28 This provision has resulted in some US companies simply ignoring Australian judgments or obtaining judgments from American courts, meaning that the company does not have to comply with the Australian judgment. ${ }^{29}$ In the absence of global agreement on cross-border jurisdictional issues, the cross-border enforceability of judgements against social media companies will always be a thorn in the side of litigants.

\section{Burrows v Houda}

\subsection{Facts}

The facts in this matter are not very clear as the court did not canvass the facts thoroughly. ${ }^{30}$ This is probably because this is merely a preliminary ruling on the ability of the comments to be regarded as defamation and not a complete consideration of all the elements of the defamation action. These preliminary rulings allow for the cost of proceedings to be kept down, as they encourage parties to settle the matter prior to a full hearing of it.

28 Section 230 of the Communications Decency Act 47 of 2012. See, also, Fair Hons $v$ Roommates.com $521 \mathrm{~F} 3 d$ 1157, 1166 (9th Cir 2008); FTC v Accusearch Inc. $570 \mathrm{~F}$ 3d 1187, 1197 (10th Cir 2009); Jones v Dirty World Entertainment Recordings LLC 755 F 3d 398 (6th Cir 2014) 88, 401-402, and Kimzey v Yelp Inc. 21 F Supp. 3d 1120, 1123 (WD Wash 2014).

29 Douglas 2019 https://theconversation.com/a-push-to-make-social-mediacompanies-liable-in-defamation-is-great-for-newspapers-and-lawyers-but-not-you127513. This strategy has also been pursued by Google in other jurisdictions for e.g. Canada in the cases of Google Inc. v Equustek Solutions Inc. 2017 SCC 34 and 
The plaintiff, Zali Burrows, is a fairly well-known Australian lawyer. ${ }^{31}$ The defendant, Adam Houda, is also a fairly well-known Australian criminal lawyer. The Herald, an Australian newspaper, had published an article in which it reported on a judge's criticism of the plaintiff's conduct in a legal matter before him and his suggestion that her conduct be referred to the Law Society for potential disciplinary action. Houda is being sued by the plaintiff in respect of two Twitter posts made in regard to links to this Herald article on 27 May 2020 and 28 July 2019.

It is unclear from the judgment what the actual post on 27 May 2020 was. From a reading of the case and a perusal of the attachments submitted to the court, labelled as "MCO A" and "MCO B", it is submitted that the 27 May 2020 post was a link to the Herald newspaper article. This post of the defendant received "retweets, 'likes' and, in particular, a reply which asked: 'July 2019 story. But what has happened to her since?' The defendant's response is the emoji commonly referred to as 'zipper-mouth face'". ${ }^{32}$

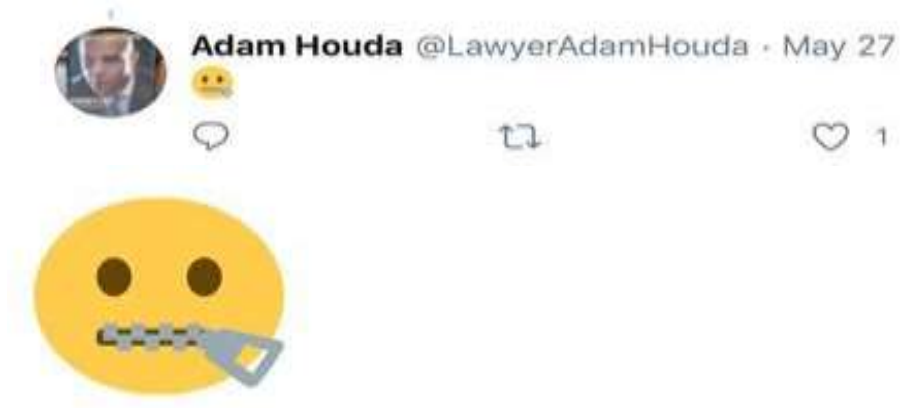

Image 1 taken from Burrows judgment.

Three comments were also made by third parties as responses to Houda's post. The first reply made the statement "'Judge Wilson recommended Ms Burrows' clients be banned for life by ASIC and prosecuted for signing affidavits they knew to be false', followed by a series of hashtags and links to other Twitter users. This is followed by the words 'tick-tock' and an emoji showing a clock". ${ }^{33}$ This post also contained two document stubs.

31 Whitbourn 2020 https://www.smh.com.au/national/judge-considers-zipper-mouthemoji-in-sydney-lawyers-defamation-fight-20200828-p55q7x.html. 
The second reply consisted of the third party utilising the "retweet with comment" option on Twitter to republish Houda's post. The additional comment of the third party consisted of the use of three emojis. These emojis were "collision", "face with tears of joy", and "ghost".

\section{Bazzio101 @Bazzio101· May 27

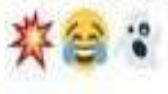

Image 2 taken from Burrows judgement.

The third reply from a third party also "retweeted with comment" Houda's post and added the words "Ohmigod bro!!!!!". 34
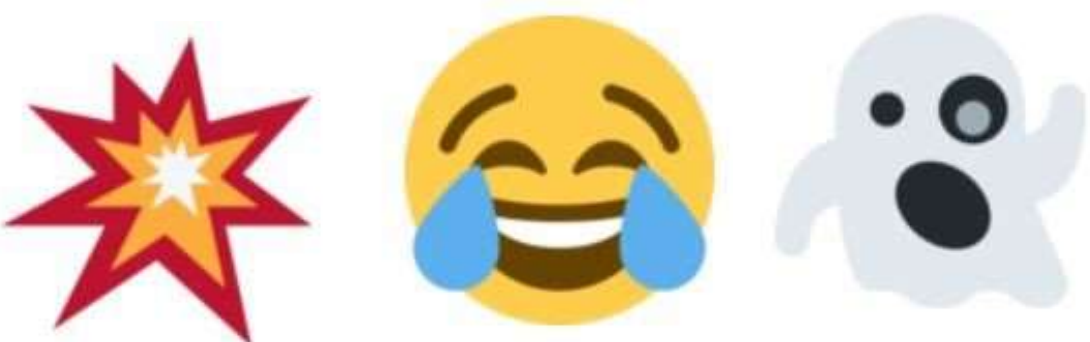

Image 3 taken from Burrows judgement.

The 28 July 2020 tweet was a response by a third party to Houda's tweet, in which this user stated "Outright crims - signing false affidavits FFS". ${ }^{35}$

The court noted that the defendant did not challenge the inclusion of the posts from third parties as part of the defamation claim against himself.

\subsection{Judgment}

Gibson DCJ stated that she would approach the topic of whether an emoji could be considered to be defamatory with care, as this was the first time that an Australian court had been asked to rule on the issue of whether an emoji could be considered to be defamatory.

Gibson DCJ then proceeded to investigate the meaning an ordinary and reasonable Twitter user would assign to the emoji symbols. In doing this she consulted an internet dictionary known as Emojipedia. Gibson DCJ states that:

$34 \quad$ Burrows $v$ Houda 2020 NSWDC 485 para 16.

35 From MCO A submitted to the court as evidence in Burrows $v$ Houda 2020 NSWDC 485. 
[a]lthough there has been some academic criticism of judges for referring to sources such as Wikipedia...the nature of modern communications makes consultation of internet dictionaries, such as Emojipedia, a necessary step for the trier of fact who seeks to determine what the ordinary reasonable Twitter reader would make of the use of these symbols. ${ }^{36}$

Gibson DCJ then proceeded to discuss the difference between an emoticon and an emoji. She states:

An 'emoticon' is a portmanteau term (from 'emotional icon') for pictures made from punctuation marks, letters and numbers to create an image displaying a sentiment and predates the internet as signs....can be created with a keyboard...[a]n emoji is a more recent invention, consisting of pictographs of faces, objects and symbols...[t]his results in the definition: 'a small digital image or icon used to express an idea, emotion, etc., in electronic communications.' Emoji are used in addition to other meaning-conferring tools, such as hashtags and buttons for 'like' or 'retweet'. ${ }^{37}$

The court then considered the English judgment in the Bercow case, in which the court was called upon to decide on the meaning of an "innocent face" emoticon, which took the form of words rather than symbols. ${ }^{38}$ This case will be discussed below.

Gibson DCJ in the Burrows judgment then proceeded to determine whether it was appropriate for a judge to decide on the meaning of an emoji without the assistance of expert evidence or jury input. She did not consider the use of an expert to be necessary in this case, for the following reasons: firstly, neither of the parties had suggested that an expert should be called and as such she did not wish to impose this on them; and secondly, Australia already had rulings regarding the meaning of emoji and other non-verbal tools (e.g. the like button and hashtags) in other areas of law not involving defamation and it had not been a requirement in those cases that an expert be called.

She also expressed the opinion that emojis have largely replaced emoticons and that the "'zipper-mouth face' emoji has a meaning to denote 'a secret' or 'stop talking', in circumstances where a person impliedly knows the answer but is forbidden or reluctant to answer." 39

Dibson DCJ then considered the emojis used by the third parties who replied to Houda's tweet. She concluded that the words "tick-tock" accompanied by the picture of the clock implied that the clock was ticking for the plaintiff.

\footnotetext{
$36 \quad$ Emojipedia $2020 \mathrm{https}: / /$ emojipedia.org/.

37 Burrows $v$ Houda 2020 NSWDC 485 paras 20-21.

38 Lord McAlpine of West Green v Bercow 2013 EWHC 1342 (QB).

$39 \quad$ Burrows $v$ Houda 2020 NSWDC 485 para 31.
} 
She then considered the tweets of the second reply, being the "collision emoji, the face with tears of joy emoji and the ghost emoji". She noted their meanings as per Emojipedia, but stated that she would not be bound to these strictly, as the meanings conveyed by a publication are a matter of a more extensive impression.

She described the emojis meaning as per Emojipedia as follows:

'Collision'...may be used to illustrate a clash but is commonly used to represent something is excellent or exciting in some way...'Ghost' which indicates something fun or goofy...the raised arms have resulted in its use to indicate 'an excited Yay!'40

The Court did not define what "face with tears of joys" meant. It is submitted that this was probably because this emoji is very popular, and its meaning is both well-known and self-explanatory.

The plaintiff submitted to the court that Houda's tweets and the subsequent responses to these tweets created a suggestion that she was facing a potential legal battle after a judge had made critical comments in respect of her competency as a lawyer and/or that the plaintiff had committed an act of misconduct during a court case and that the judge had recommended that she be referred to a lawyers' professional body for possible disciplinary sanction and/or that the plaintiff was a criminal who signs false affidavits and/or that the "plaintiff's conduct as a lawyer during court proceedings over which Judge Wilson presided was so poor that the judge recommended that her clients be banned for life by ASIC and prosecuted for signing affidavits that they knew to be false." 41

The defendant's counsel submitted that none of the defendant's tweets gave rise to a suggestion that the plaintiff was being, or was likely to be, disciplined by any professional body for her conduct. Although the defendant had shared the "stub" (i.e. the link) to the Herald article, he made no additional comment with the exception of three dots (...) and a tag labelled "\#auspol". They argued that neither the dots nor the hashtag was sufficient to give rise to any of the implications raised by the plaintiff. In addition, they argued that the "zipper-mouth face" "conveys nothing other than the defendant cannot reply."42

The plaintiff did not agree with this argument, pointing out that the "zippermouth face" was made as a response to an enquiry in regard to the alleged disciplinary inquiry. In addition, they argued that the defendant had posted

Burrows $v$ Houda 2020 NSWDC 485 para 34.

Burrows $v$ Houda 2020 NSWDC 485 para 11.

Burrows v Houda 2020 NSWDC 485 para 37. 
the stub to the article almost a year after the article had originally been posted by the Herald. The plaintiffs submitted:

[t]hat this 'zipper-mouth face' is worth a thousand words - the emoji implies that there has been a finding damaging to the plaintiff, but the defendant is not at liberty to disclose the result, and instead must hint at it by posting the newspaper story from the previous year and using the 'zipper-mouth face', so the reader can guess the rest...this Delphic response is the equivalent of shouting 'fire' in a crowded theatre, giving rise to a defamatory meaning which is further inflamed by the three following comments. ${ }^{43}$

The court ruled that the defendant's comments, when read in context, were capable of being understood as stating that the plaintiff was facing disciplinary action by a professional body. The defendant had posted a stub that was almost a year old, and when asked about the outcome of this article he posted the "zipper-mouth face" in reply to that question. The court held that this "is a case where 'joining the dots'...to achieve the meaning is a particularly likely exercise when carried out on a social media site, where the exchange of such information is more likely than a serious publication to contain hints of a sensational nature." 44

The court then proceeded to consider the plaintiff's submissions that the defendant's comments suggested that she was a criminal who signs false affidavits and/or that her poor conduct as a lawyer led to the judge recommending that her clients be banned by ASIC and be prosecuted for knowingly signing false affidavits. ${ }^{45}$

The court held that the tweets in question were reasonably capable of conveying these suggestions and stated:

I am satisfied that the ordinary reasonable social media reader would infer that, while the clients 'signed' the false affidavits, the plaintiff, who was a solicitor reported to be in trouble with the judge, would also reasonably have been seen to be in trouble for her role in the preparation of the offending affidavits and/or their presentation to the court. This is underlined by the words 'tick tock' and use of the 'clock face three o' clock' emoji, which infer that the plaintiff's time (in terms of being dealt with for her wrongdoing) was up. The third and fourth posts add further emoji and comment to the defendant's post when they retweet it. They reinforce that the plaintiff's conduct is extremely serious and the subject of professional sanctions... I am satisfied that, in circumstances where the tweet clearly identifies that there is to be a prosecution for false swearing of affidavits, the ordinary reasonable social media reader would infer that one of those likely to be prosecuted would be the plaintiff, particularly given the 'tick tock' and the three excited emoji in the third reply. This

43 Burrows $v$ Houda 2020 NSWDC 485 paras 39-40.

$44 \quad$ Burrows $v$ Houda 2020 NSWDC 485 para 41. 
would amount to conduct of a criminal nature, and not merely professional misconduct. ${ }^{46}$

The court thus concluded that the "zipper- mouth" emoji could be defamatory.

\section{English law: Lord McAlpine of West Green $v$ Bercow [2013] EWHC 1342 (QB)}

In November 2012 the British Broadcasting Corporation (popularly known as the $\mathrm{BBC}$ ) reported that "a leading Conservative politician from the Thatcher years" was one of the abusers in a recently reported child sex abuse scandal. ${ }^{47}$ The BBC did not explicitly name the politician it was referring to, but many individuals were quick to identify Lord McAlpine as this unnamed politician in posts on Facebook and Twitter. Sally Bercow was one of the individuals who posted a Tweet asking "Why is Lord McAlpine trending? *innocent face*". 48 It was later confirmed that Lord McAlpine was not the individual in the report who had abused the young boy and he then decided to pursue a defamation action against the media corporations and individual users who had identified him as a paedophile. ${ }^{49} \mathrm{He}$ eventually reached settlement with the $\mathrm{BBC}$ and other media corporations and allowed individuals who had less than 500 followers to settle the matter by making a £25 donation to a charity. He then decided to pursue individual actions with users who had more than 500 followers. Ms Bercow had more than 500 followers - she in fact had 56000 followers as at 4 November 2012 - but she refused to admit that she had defamed Lord McAlpine, nor was she willing to enter into a settlement. Lord McAlpine then instituted a defamation action against her..$^{50}$

Sally Bercow 0

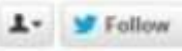

Why is Lord McAlpine trending? "innocent

face*

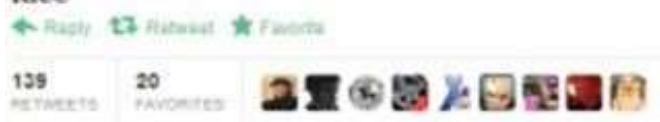

Image 4 taken from Burrows judgement.

\footnotetext{
$46 \quad$ Burrows $v$ Houda 2020 NSWDC 485 paras 45-47, 49.

$47 \quad$ Lord McAlpine of West Green v Bercow 2013 EWHC 1342 (QB) para 15.

$48 \quad$ Lord McAlpine of West Green v Bercow 2013 EWHC 1342 (QB) para 3.

49 Lord McAlpine of West Green v Bercow 2013 EWHC 1342 (QB) paras 15, 16. See also Baksi 2019 https://www.theguardian.com/law/2019/may/28/landmarks-in-law. Lord McAlpine of West Green v Bercow 2013 EWHC 1342 (QB) para 10.
} 
Lord McAlpine alleged that Bercow's tweet carried the innuendo that he was a "paedophile who was guilty of sexually abusing boys living in care."51

Bercow denied that her comment was defamatory and stated that she was simply asking a question in her tweet. She further accepted that her question implied that Lord McAlpine was trending (on Twitter), but denied that this was defamatory in any way as she did not suggest a reason as to why Lord McAlpine was trending. ${ }^{52}$

The sole issue in this case was to determine whether the tweet could be considered as defamatory.

The court held that:

It is common ground between the parties that the words 'innocent face' are to be read like a stage direction, or an emoticon (a type of symbol commonly used in a text message or email). Readers are to imagine that they can see the Defendant's face as she asks the question in the Tweet. The words direct the reader to imagine that the expression on her face is one of innocence, that is an expression which purports to indicate (sincerely, on the Defendant's case, but insincerely or ironically on the Claimant's case) that she does not know the answer to her question. ${ }^{53}$

The court then proceeded to examine the meaning that the ordinary reasonable Twitter follower of Bercow would place on her tweet. The court concluded that the "innocent face" emoticon was not an innocent question, but rather that her tweet would be viewed in the light of the circumstances surrounding the tweet. ${ }^{54}$ At the point in time when she had tweeted, the plaintiff's name was trending as there was a flurry of articles in the press in which an unnamed person was accused of being a paedophile. Thus any Twitter user who read her post would interpret her question not as an innocent query, but rather as an insinuation that the plaintiff was the unnamed person and that he had been publicly exposed for conduct for which he was guilty and that she believed this to be righteous. ${ }^{55}$

The court held that English law accepted that a question could be understood to convey a defamatory meaning, ${ }^{56}$ and stated:

In my judgment, the reasonable reader would understand the words 'innocent face' as being insincere and ironical. There is no sensible reason for including those words in the Tweet if they are to be taken as meaning that the Defendant

$51 \quad$ Lord McAlpine of West Green v Bercow 2013 EWHC 1342 (QB) para 33.

$52 \quad$ Lord McAlpine of West Green v Bercow 2013 EWHC 1342 (QB) para 34.

$53 \quad$ Lord McAlpine of West Green v Bercow 2013 EWHC 1342 (QB) para 7.

$54 \quad$ Lord McAlpine of West Green v Bercow 2013 EWHC 1342 (QB) paras 84, 85.

55 It was later confirmed that Lord McAlpine was not the unnamed party in the news articles and that he was innocent of the accusations that had been made against him. 
simply wants to know the answer to a factual question... I find that the Tweet meant, in its natural and ordinary defamatory meaning, that the Claimant was a paedophile who was guilty of sexually abusing boys living in care... If I were wrong about that, I would find that the Tweet bore an innuendo meaning to the same effect. ${ }^{57}$

Bercow finally settled the matter with Lord McAlpine for the sum of $£ 15000$.

\section{South Africa}

Currently our South African courts have not yet had to hear any matter involving emojis, nor have they been called upon to decide whether an emoji could be considered defamatory. I will briefly canvass the South African law of defamation before hypothesising the potential reaction of our courts to the factual scenario as presented in Burrows $v$ Houda.

Defamation is the unlawful, intentional publication of words or conduct which have the effect of injuring another person's reputation. ${ }^{58}$ The injury to the person's reputation is judged objectively, in that a reasonable member of society must think lesser of the person due to the defamatory statement or conduct. ${ }^{59}$

In order to establish a defamation action, a plaintiff must prove "(a) the wrongful and (b) intentional (c) publication of (d) a defamatory statement (e) concerning the plaintiff". 60

Once the plaintiff proves the publication of a defamatory statement which refers to him/her, then the wrongfulness and fault element are presumed to have been proven in favour of the plaintiff, and should the defendant wish to rebut this presumption, then he/she must raise a defence to exclude the presence of wrongfulness or intention. ${ }^{61}$

The truthfulness of the statement/conduct is not a prerequisite for the statement/conduct to be held to be defamatory, and the defendant can be held liable for defamation even for the publication of truthful information. ${ }^{62}$

\subsection{Publication}

In order to prove publication, the plaintiff must show that the defamatory statement or conduct was communicated to a third party. Publication need

$57 \quad$ Lord McAlpine of West Green v Bercow 2013 EWHC 1342 (QB) paras 84, 90 and 91.

Neethling and Potgieter Neethling-Potgieter-Visser Law of Delict 352.

Mahomed $v$ Jassiem 19961 SA 673 (A).

Khumalo v Holomisa 20025 SA 401 (CC) para 18.

Jackson $v$ NICRO 19763 SA 1 (A).

Mahomed v Jassiem 19961 SA 673 (A) 694; National Media Ltd v Bogoshi 19984

SA 1196 (SCA) 1218, and Khumalo v Holomisa 20025 SA 401 (CC) 414. 
not be intentional, provided it is foreseeable. ${ }^{63}$ Publication occurs only if the third party understands the publication to be defamatory. However, it is not necessary that he understand the material to be defamatory at the time he first hears or reads the words. If he later discovers the meaning of the material to be defamatory, then the requirement of publication will have been satisfied. ${ }^{64}$

In Burrows the publication occurred via a publication of the tweet on Twitter. In terms of South African law, publication would not be an issue. Once a tweet is published on Twitter it is generally available for any viewer to see, regardless of whether such a viewer has a Twitter account or not. The user does have an option to limit the audience to his post. However, it is submitted that even should a user utilise this option and limit his audience, the tweet would still have been published to third parties.

A person who repeats the defamatory statement of another is also regarded as a publisher of that material. In Burrows, the postings were made by Houda and other third parties. Houda did not deny ownership of his Twitter profile, nor did he raise the fact that some of the postings were made by third parties and not himself. ${ }^{65}$

Should these issues arise in a South African court they would not be novel as our courts have already had to deal with issues of the ownership of online profiles and anonymous third-party postings in Dutch Reformed Church Vergesig $v$ Sooknunan. ${ }^{6}$

In this case the defendant, Sooknunan, denied that he was the owner of the Facebook page on which the defamatory statements were published and argued that even if he were the owner of the page, he was not responsible for the posts of other anonymous third parties who might have posted defamatory material on the page. The court adopted a pragmatic approach in establishing the ownership of disputed profiles on Facebook. ${ }^{67}$ Should a dispute arise over the ownership of a Twitter profile in South Africa, it is submitted that the court would in practice consider the content and pictures on the profile to determine ownership.

$63 \quad$ Pretorius $v$ Niehaus 19603 SA 109 (C) 113.

$64 \quad$ Vermaak $v$ Van der Merwe 19813 SA $78(\mathrm{~N})$.

65 This is apparent from a reading of the judgement in Burrows $v$ Houda 2020 NSWDC 485.

66 Dutch Reformed Church Vergesig v Sooknunan 20126 SA 201 (GSJ).

67 Singh 2014 Obiter 626. 
Sooknunan also argued that he should not be responsible for the posts of third parties on the page. The "court dealt with this issue by holding that the creator of a Facebook profile is responsible for posts made on the profile as his or her role is akin to that of a publisher who has made a forum available for the posting of unlawful content." ${ }^{68}$ Thus, in South Africa a defendant in Houda's position, could be held liable for the defamatory postings of third parties on his Twitter profile.

\subsection{Defamatory statement}

The plaintiff also has to establish that the defendant published statements or conduct that could be regarded as defamatory. This publication must both actually harm the plaintiff's good name or reputation and be objectively unreasonable. ${ }^{69}$

In order to determine if the words or conduct complained of are defamatory in nature, a court must explore the meaning of the words or conduct. This meaning could firstly be its primary meaning, which is the ordinary meaning that a reasonable reader or listener would ascribe to the words or conduct. A court must not only look at what the words or conduct expressly state, but also at any implications that arise from it. ${ }^{70}$ Secondly, in appropriate circumstances the court must consider whether the words or conduct may have a secondary meaning. A secondary meaning is usually words or conduct that may appear prima facie to be innocent, but are in fact defamatory due to an innuendo, or a special meaning, which is understandable to the reader/listener. In addition, the words may also be defamatory in their primary meaning, but carry an additional sting due to the innuendo. ${ }^{71}$

In a situation where words or conduct are capable of multiple meanings, the court will attempt to determine, on a balance of probabilities, the meaning that the ordinary reader or listener would ascribe to the words. ${ }^{72}$

Once the court has determined the primary and/or secondary meaning of the words or conduct, it will attempt to determine if those words or conduct

\footnotetext{
$68 \quad$ Singh 2014 Obiter 626.

69 Neethling, Potgieter and Visser Neethling's Law of Personality 135. This is judged in an objective manner and means that the injury to a person's reputation must have factually caused a reasonable member of society to think lesser of him; i.e. that his reputation has been lowered in their estimation.

Argus Printing \& Publishing Company v Esselen's Estate 19942 SA 1 (A) 20; Sindani $v$ van der Merwe 20003 SA 494 (W) 497.

Loubser et al Law of Delict 423.

Demmers v Wyllie 19801 SA 835 (A) 842-843.
} 
can be held to be defamatory. In order to do so the court will determine whether the words or conduct lower the plaintiff in the estimation of rightthinking persons generally. ${ }^{73}$ In more esoteric defamation matters which concern words or conduct that might be defamatory to certain subcultures or sectors of society only, our courts will consider whether the words or conduct are defamatory to "substantial and respectable" sections of South African society - provided their views are not contrary to good morals. ${ }^{74}$

A plaintiff will usually be considered to be lowered in the estimation of rightthinking persons generally if the words or conduct reflect upon his moral character ${ }^{75}$ or if they subject him to hatred, ${ }^{76}$ contempt $^{77}$ or ridicule. ${ }^{78}$

Could an emoji be considered as defamatory in South Africa? It is submitted that the issue of defamatory matter will be the crux of the law in reaching this conclusion. Any words or conduct can be considered as defamatory in South Africa, provided that the publication of this statement or conduct lowers the plaintiff's reputation. Our courts have already recognised that a digitally altered photo could be considered to be defamatory. ${ }^{79}$ It is thus submitted that provided the plaintiff can establish that the publication of the emoji caused his reputation to be lowered, there would be no obstacle to our court's extending our current legal principles to an act of defamation perpetrated via the medium of an emoji.

Below, I canvass some of the issues I believe could arise if a defamation matter involving an emoji arises in a South African court.

The popularity of emojis in modern conversations cannot be denied. While the meaning behind the most popular emojis can be said to be widely understood, the same cannot be said about the meanings behind less popular emojis. An example is the "smiling face with open mouth and tightly shut eyes" emoji, which in one study had $54 \%$ of respondents state that it was a positive emoji - whereas $44 \%$ of respondents labelled it as a negative emoji. ${ }^{80}$

\footnotetext{
$73 \quad$ Botha v Marais 19741 SA 44 (A) 49.

$74 \quad$ Mahomed $v$ Jassiem 19961 SA $673(\mathrm{~A})$.

75 SAUK v O'Malley 19773 SA 394 (A) - implying criminal conduct; Penn v Fiddel 1954 4 SA 498 (C)- implying dishonest conduct; Tothill v Foster 1925 TPD 857 - implying immorality; Sokhulu v New Africa Publications Ltd 20014 SA 1357 (W) 1359 morality changes as society's conceptions of morality change. Gayre v SAAN 19633 SA 376 (T).

Rutland v Jordan 19533 SA 806 (C) 814; Muller v SAAN 19722 SA 589 (C) 591; Mangope $v$ Asmal 19974 SA 277 (T). Le Roux v Dey 20113 SA 274 (CC). McMahon and Kirley 2019-2020 MJLST 70.
} 
If such a matter were to arise in a South African court, it is submitted that the court would attempt to assign to the emoji the meaning which an ordinary reasonable reader of an emoji on that medium would assign to it. This might involve the court's entering an exploration of whether the average Twitter user differs from the average Facebook or WhatsApp user. There have been many overseas studies which attempt to determine the meaning that an average user assigns to emojis. However, it could be argued that these studies are of limited use as they did not contain South African study subjects, who may hold quite different views of the emojis being studied.

One should also bear in mind that different countries and cultures may assign different meanings to the same emoji, and subtleties and different nuances in cultural interpretations may lead to miscommunications if the parties or the persons to whom the potentially defamatory emoji is communicated share different cultures or countries of origin. This would be especially problematic in South Africa - not only when South African citizens communicate with people from other countries, but also in communications among South Africans, as we have such a rich and diverse citizenship.

Additionally, it should be noted that the same emoji can bear a very different coded meaning to members of subcultures. For example, a crown emoji can be thought of as a royal symbol to normal users, whereas that same symbol in the sex-trafficking subculture means that the lady who is being trafficked is under the control of a "pimp". 81

It is submitted that the points raised above should not deter our courts from considering the defamatory aspect of an emoji. Our courts should use existing principles and adapt these to online usage customs and to customs among subcultures. Our current principles have been developed over a period of time and are solidly rooted in our Roman-Dutch law and constitutional principles, and can be easily adapted to new problems that are encountered with modern technology.

Most users are also unaware that the senders and recipients of emojis do not always see the exact same emoji on their devices - especially if each of them uses different devices or operating software/platforms. ${ }^{82}$ As some emoji images are considered to be intellectual property, some of them are depicted differently on different platforms. Let us take a very commonly used emoji as an example - the face with rolling eyes emoji. On an Apple device

81 Goldman 2019 https://blog.ericgoldman.org/archives/2019/03/two-examples-ofhow-courts-interpret-emojis.htm; Emojipedia 2020 https://emojipedia.org/

82 Goldman 2018 Wash L Rev 1227. 
this emoji will appear with the eyeballs mid centre at the top of the eyes with a straight mouth. On a device utilising Google as the platform, this very same emoji will appear with larger eyeballs that are still on the top of the eye, but which are now slightly to the left of the eye instead of the centre of the eye. The mouth is also different and is now not straight, but rather is downturned. This same emoji on a device utilising the Samsung software platform is also very different with much larger and more detailed eyes that are placed differently from the eye locations of the same emoji in both the Apple and the Google devices. The Samsung device emoji also has eyebrows and a mouth that are completely different from those of the same emoji as depicted in the other two devices - most importantly, its mouth is a smiling one. ${ }^{83}$ It is thus possible for the same emoji to elicit different reactions and meanings between senders and recipients who are using different devices. While this is usually insignificant, it can sometimes lead to miscommunication and unintended consequences. ${ }^{84}$ If such a scenario should arise in South Africa, it is submitted that our courts would have to carefully consider the fault requirement for defamation and canvass any potential defences that the defendant could raise due to possible contamination of the emoji selected by the defendant (sender) and received by the recipient due to their having different devices or using different software platforms.

\subsection{Reference to plaintiff}

This element is not usually a problematic one as the plaintiff merely has to prove that the ordinary reasonable reader or listener would associate the defamatory words or conduct with them. ${ }^{85}$

In the Burrows case, Burrows would have no difficulty in South Africa in showing that the posts complained of referred to her, as the ordinary reader of the posts could clearly conclude from the context that Burrows was the person to whom the posts referred.

\subsection{Possible defences to defamation in South Africa}

There is no closed list of defences which a defendant may raise to a defamation claim in South Africa. The most commonly raised defences to defamation claims in South Africa may be divided into two categories -

83 For a visual depiction of these three emojis and the differences between other emojis on different devices, please see Okrent 2017 https://www.mentalfloss.com/article/ 516048/22-emojis-look-completely-different-different-phones. Diaz 2008 https://gizmodo.com/a-cellphones-missing-dot-kills-two-people-putsthree-m-382026. 
firstly those which attempt to rebut the wrongfulness element of the defamation, and secondly those which attempt to rebut the fault element of the defamation.

A defendant who is attempting to rebut wrongfulness could raise any of the following defences: Truth for the public benefit, ${ }^{86}$ fair comment ${ }^{87}$ or qualified privilege. ${ }^{88}$ In addition, if the defendant is a media entity, it may also raise the defence that the publication was reasonable. ${ }^{89}$

A defendant who is attempting to rebut the fault element may raise any of the following defences to show that he lacked the intention to defame the plaintiff: mistake (of both law and fact), ${ }^{90}$ jest $^{91}$ or rixa (provocation). ${ }^{92}$

\subsection{Possible South African court awards}

While most plaintiffs consider an award of damages to be the only or the main outcome of a defamation action, our courts also have the ability to award other orders.

Our courts have approved interdicts to remove offensive posts from social media sites. ${ }^{93}$ Our courts have also held that they have the ability to order the defendant to tender an apology to the plaintiff ${ }^{94}$ and that an apology tendered in the same medium in which the plaintiff was defamed could completely clear the plaintiff's name. ${ }^{95}$

It is thus submitted that should a defendant find himself in Houda's position in South Africa, he should consider the option of retracting his tweet and apologising for the tweet on Twitter. Even if such an action does not completely exonerate him, the court will take this retraction and apology into account when considering an award of damages.

\section{Conclusion}

It is submitted that our courts in South Africa would be willing to hold that an emoji could be considered as defamatory in our law. In order to reach this

Johnson v Rand Daily Mails 1928 AD 190 204; Geyser v Pont 19684 SA 67 (W) 68. Crawford v Albu 1917 AD 102; Marais v Richard 19811 SA 1157 (A). O v O 19954 SA 482 (W) 492; Pogrund v Yutar 19672 SA 564 (A) 570; Joubert v Venter 19851 SA 654 (A) 697.

$89 \quad$ National Media Ltd v Bogoshi 19984 SA 1196 (SCA).

$90 \quad$ Maisel $v$ van Naeren 19604 SA 836 (C) 840; Minister van Veiligheid en Sekuriteit v Kyriacou 20004 SA 337 (O) 341-342.

$91 \quad$ Peck v Katz 19572 SA 567 (T) 572-573.

92 Neethling, Potgieter and Visser Neethling's Law of Personality 160, 164-166.

$93 \quad$ Heroldt $v$ Wills 20132 SA 530 (GSJ).

$94 \quad$ Le Roux v Dey 20113 SA 274 (CC) paras 150, 195, 197, 199, 202, 203.

$95 \quad$ Isparta $v$ Richter 20136 SA 529 (GP) para 41.
} 
conclusion, our courts would not have to wait for new legislation, nor would they need to develop new principles, as our current law could be easily adapted to solve new issues arising out of the use of technology. ${ }^{96}$ Previous cases have already shown that our courts do not consider the right of free speech to be unfettered on social media sites, and that the right to free speech must always be balanced against another's right to reputation. ${ }^{97}$ While the popularity of emoji usage in everyday text messaging and in posts on social media is increasing at a tremendous rate, South African users should heed the warning of the Burrows and Bercow cases and carefully consider whether the emoji they are choosing to transmit could be perceived as being defamatory.

\section{Bibliography}

\section{Literature}

Goldman 2018 Wash L Rev

Goldman E "Emojis and the Law" 2018 Wash L Rev 1227-1292

Kirley and McMahon 2018 Tenn L Rev

Kirley E and McMahon M "The Emoji Factor: Humanizing the Emerging Law of Digital Speech" 2018 Tenn L Rev 517-570

Loubser et al Law of Delict

Loubser $\mathrm{M}$ et al The Law of Delict in South Africa $3^{\text {rd }}$ ed (Oxford University Press Cape Town 2017)

McMahon and Kirley 2019-2020 MJLST

McMahon MM and Kirley EA "When Cute Becomes Criminal: Emoji, Threats and Online Grooming" 2019-2020 MJLST 37-92

Neethling and Potgieter Neethling-Potgieter-Visser Law of Delict

Neethling $\mathrm{J}$ and Potgieter JM Neethling-Potgieter-Visser Law of Delict $7^{\text {th }}$ ed (LexisNexis Durban 2015)

Neethling, Potgieter and Visser Neethling's Law of Personality

Neethling J, Potgieter JM and Visser PJ Neethling's Law of Personality $2^{\text {nd }}$ ed (LexisNexis Durban 2005)

Pelletier 2016 Wash U J L \& Pol'y

Pelletier N "The Emoji that Cost $\$ 20,000$ : Triggering Liability for Defamation on Social Media" 2016 Wash U J L \& Pol'y 227-254

$96 \quad$ Roos and Slabbert 2014 PELJ 2844.

97 Heroldt v Wills 20132 SA 530 (GSJ); Isparta v Richter 20136 SA 529 (GP); Dutch Reformed Church Vergesig v Sooknunan 20126 SA 201 (GSJ). 
Roos and Slabbert 2014 PELJ

Roos A and Slabbert M "Defamation on Facebook: Isparta v Richter 2013 (6) SA 529 GP" 2014 PELJ 2844-2868

Singh 2014 Obiter

Singh PP "Social Media and the Actio Injuriarium in South Africa - An Exploration of New Challenges in the Online Era" 2014 Obiter 616-628

Stark and Crawford $2015 S M+S$

Stark $L$ and Crawford K "The Conservatism of Emoji: Work, Affect, and Communication" 2015 SM + S 56-60

\section{Case law}

Al Muderis v Duncan (No 3) 2017 NSWSC 726

Argus Printing \& Publishing Company v Esselen's Estate 19942 SA 1 (A)

Botha v Marais 19741 SA $44(\mathrm{~A})$

Burrows v Houda 2020 NSWDC 485

Crawford v Albu 1917 AD 102

Demmers v Wyllie 19801 SA 835 (A)

Duffy v Google Inc 2015125 SASR 437

Dutch Reformed Church Vergesig v Sooknunan 20126 SA 201 (GSJ)

Fair Hons v Roommates.com 521 F 3d 1157 (9th Cir 2008)

FTC v Accusearch Inc 570 F 3d 1187 (10th Cir 2009)

Gayre v SAAN 19633 SA 376 (T)

Geyser v Pont 19684 SA 67 (W)

Google Inc v Duffy 2017129 SASR 304

Google Inc v Equustek Solutions Inc 2017 SCC 34

Google LLC v Equustek Solutions Inc Case No 5:17-cv-04207-EJD

Hassen v Post Newspapers (Pty) Ltd 19653 SA 562 (W)

Heroldt v Wills 20132 SA 530 (GSJ) 
Isparta v Richter 20136 SA 529 (GP)

Jackson v NICRO 19763 SA 1 (A)

Johnson v Rand Daily Mails 1928 AD 190

Jones v Dirty World Entertainment Recordings LLC 755 F 3d 398 (6th Cir 2014)

Joubert v Venter 19851 SA 654 (A)

Khumalo v Holomisa 20025 SA 401 (CC)

Kimzey $v$ Yelp Inc $21 \mathrm{~F}$ Supp 3d 1120 (WD Wash 2014)

Lee $v$ Wilson 193451 CLR 276; 1934 HCA 6

Lewis v Daily Telegraph Ltd 1964 AC 234

Le Roux v Dey 20113 SA 274 (CC)

Lord McAlpine of West Green v Bercow 2013 EWHC 1342 (QB)

Mahomed $v$ Jassiem 19961 SA 673 (A)

Maisel $v$ van Naeren 19604 SA 836 (C)

Mangope $v$ Asmal 19974 SA 277 (T)

Marais v Richard 19811 SA 1157 (A)

Minister van Veiligheid en Sekuriteit v Kyriacou 20004 SA 337 (O)

Mograbi v Miller 19564 SA 239 (T)

Muller v SAAN 19722 SA 589 (C)

National Media Ltd v Bogoshi 19984 SA 1196 (SCA)

O v O 19954 SA $482(\mathrm{~W})$

Peck v Katz 19572 SA 567 (T)

Penn v Fiddel 19544 SA 498 (C)

People v Smith No B284766, 2019 Cal App Unpub LEXIS 1691, at *2 (Cal Ct App Mar 12, 2019)

Pogrund $v$ Yutar 19672 SA 564 (A) 
Pont v Geyser 19682 SA 545 (A)

Pretorius v Niehaus 19603 SA 109 (C)

Rutland $v$ Jordan 19533 SA 806 (C)

SAAN v Estate Pelser 19754 SA 797 (A)

SAUK v O'Malley 19773 SA 394 (A)

Sims v Wran 19841 NSWLR 317

Sindani v Van der Merwe 20003 SA 494 (W)

Sokhulu v New Africa Publications Ltd 20014 SA 1357 (W)

Speight v Gosnay 189160 LJQB 231

State $v$ Atchison $15 \mathrm{Neb}$ App 422 (2007)

Tothill v Foster 1925 TPD 857

Trkulja v Google LLC 2018 HCA 25

Trkulja v Yahoo! Inc LLC 2012 VSC 88

United States v Elonis 730 F 3d 321 (3d Cir 2013)

Vermaak v Van der Merwe 19813 SA $78(\mathrm{~N})$

Voller v Nationwide News Pty Ltd; Voller v Fairfax Media Publications Pty Ltd; Voller v Australian News Channel Pty Ltd 2019 NSWSC 766

\section{Legislation}

Communications Decency Act 47 of 2012

Defamation Act of 2005

Original Model Defamation Provisions of 2005

Internet sources

Baksi 2019 https://www.theguardian.com/law/2019/may/28/landmarks-inlaw

Baksi C 2019 Sally Bercow and the First Major 'Twibel' Case https://www.theguardian.com/law/2019/may/28/landmarks-in-law accessed 5 January 2021 
Diaz 2008_https://gizmodo.com/a-cellphones-missing-dot-kills-two-peopleputs-three-m-382026

Diaz J 2008 Gizmodo_https://gizmodo.com/a-cellphones-missing-dot-killstwo-people-puts-three-m-382026 accessed 7 September 2020

Douglas 2019 https:/theconversation.com/a-push-to-make-social-mediacompanies-liable-in-defamation-is-great-for-newspapers-and-lawyers-butnot-you-127513

Douglas M 2019 A Push to Make Social Media Companies Liable in Defamation is Great for Newspapers and Lawyers, but not You https://theconversation.com/a-push-to-make-social-media-companiesliable-in-defamation-is-great-for-newspapers-and-lawyers-but-not-you127513 accessed 7 September 2020

Douglas $2020 \mathrm{https}: / /$ theconversation.com/australias-outdated-defamationlaws-are-changing-but-theres-no-revolution-yet-143532

Douglas M 2020 Australia's 'Outdated' Defamation Laws are Changing - but There's no 'Revolution' Yet https://theconversation.com/australiasoutdated-defamation-laws-are-changing-but-theres-no-revolution-yet143532 accessed 7 September 2020

Emojipedia 2020 https://emojipedia.org/

Emojipedia 2020 Emojipedia https://emojipedia.org/_accessed 7 September 2020

Goldman 2019 https://blog.ericgoldman.org/archives/2019/03/twoexamples-of-how-courts-interpret-emojis.htm

Goldman E 2019 Two Examples of How Courts Interpret Emojis https://blog.ericgoldman.org/archives/2019/03/two-examples-of-howcourts-interpret-emojis.htm accessed 7 September 2020

Okrent 2017 https://www.mentalfloss.com/article/516048/22-emojis-lookcompletely-different-different-phones

Okrent A 201722 Emojis that Look Completely Different on Different Phones__ https://www.mentalfloss.com/article/516048/22-emojis-lookcompletely-different-different-phones accessed 7 September 2020

Pelley 2019 https://www.afr.com/companies/media-and-marketing/ australia-the-defamation-capital-of-the-world-20190904-p52nuh Pelley M 2019 Australia - The Defamation Capital of the World https://www.afr.com/companies/media-and-marketing/australia-thedefamation-capital-of-the-world-20190904-p52nuh accessed 7 September 2020 
SouthFloridaReporter.com 2020 https://southfloridareporter.com/\%F0\% 9F\%98\%84-95-of-internet-users-have-used-an-emoji-over-10-billionemojis-are-sent-daily/

SouthFloridaReporter.com 2020 95\% of Internet Users have Used an Emoji. Over 10 Billion Emojis are Sent Daily https://southfloridareporter.com/\%F0\%9F\%98\%84-95-of-internet-usershave-used-an-emoji-over-10-billion-emojis-are-sent-daily/ accessed 8 September 2020

Unicode 2020 https://unicode.org/emoji/charts/emoji-counts.html Unicode 2020 Emoji Counts https://unicode.org/emoji/charts/emojicounts.html accessed 8 September 2020

Whitbourn 2020 https://www.smh.com.au/national/judge-considers-zippermouth-emoji-in-sydney-lawyers-defamation-fight-20200828-p55q7x.html Whitbourn M 2020 Judge Considers 'Zipper-Mouth' Emoji in Sydney Lawyers' Defamation Fight https://www.smh.com.au/national/judgeconsiders-zipper-mouth-emoji-in-sydney-lawyers-defamation-fight20200828-p55q7x.html accessed 7 September 2020

\section{List of Abbreviations}

MJLST

PELJ

$\mathrm{SM}+\mathrm{S}$

Tenn L Rev

Wash L Rev

Wash U J L \& Pol'y
Minnesota Journal of Law, Science and Technology

Potchefstroom Electronic Law Journal

Social Media + Society

Tennessee Law Review

Washington Law Review

Washington University Journal of Law and Policy 